Annals of International Medical and Dental Research

E-ISSN: 2395-2822 | P-ISSN: 2395-2814

Vol-8, Issue-2 | March-April 2022

DOI: 10.53339/aimdr.2022.8.2.21

Page no- 157-163 | Section- Research Article (General Surgery)

\title{
A Comparative Study between E-TEP vs IPOM Hernia Repair
}

\section{Deb Prosad Paul1*, Debashis Paul², ASM Zahidur Rahman ${ }^{3}$, Karina Rahman4, Sonia Akter ${ }^{5}$}

1Professor, Department of Surgery, Enam Medical College, Dhaka, Bangladesh. Email: drdebpaul@yahoo.com,

Orcid ID: 0000-0002-1277-0964.

${ }^{2}$ Assistant Professor, Department of Surgery, Kushtia Medical College, Kushtia, Bangladesh.

Email: pauldeba41@gmail.com,

Orcid ID: 0000-0002-7867-3294.

3Professor, Department of Surgery, City Medical College, Dhaka, Bangladesh. Email: asmrahman@gmail.com,

Orcid ID: 0000-0002-1431-5463.

${ }^{4}$ Assistant Professor, Department of Surgery, Enam Medical College, Dhaka, Bangladesh.

Email: karinarahman@gmail.com,

Orcid ID: 0000-0001-6769-3532.

${ }^{5}$ Assistant Professor, Department of Surgery, Enam Medical College, Dhaka, Bangladesh.

Email: soniyashafiq37@gmai.com,

Orcid ID: 0000-0003-3897-9819.

${ }^{*}$ Corresponding author

Received: 13 December 2021

Revised: 26 January 2022

Accepted: 05 February 2022

Published: 18 February 2022

\begin{abstract}
Background: A ventral hernia is a hernia which can be occur at any location along the midline (vertical center) of the abdomen wall. It can be classified as spontaneous (primary) or acquired (secondary). Also, there are basically 3 types of ventral hernia and these are: Epigastric or stomach area hernia, Umbilical or belly button hernia and the Incisional hernia. Material \& Methods: This was a prospective observational comparative study. The total sample size for this study 38 and among these 18 cases were from eTEP and 20 cases were from IPOM. The study period was from December 2019- December 2021. The stratified sampling method was followed for this study as an eligibility criterion for age of the respondents was set for this study. Results: The presence of co-morbidities was found in both e-TEP and IPOM. High blood pressure was seen in $7(38.89 \%)$ cases in e-TEP and $8(40 \%)$ cases in IPOM and followed by stroke in $4(22.22 \%)$ and $5(25 \%)$, Hypothyroidism in $1(5.56 \%)$ and $1(5 \%)$, Cancer in $2(11.11 \%)$ and $2(10 \%)$, Diabetes in $4(22.225)$ and $4(20 \%)$. Location of Hernia in right $7(38.89 \%)$ and $8(40 \%)$ and in left side was $11(61.11 \%)$ and $12(60 \%)$. In assessing the condition of disease, it was found that ventral hernia was in $4(22.22 \%)$ and $5(25 \%)$, Umbilical hernia in 6(33.33\%) and 6(30\%), Epigastric hernia $8(44.44 \%)$ and $9(45 \%)$. The Mean and SD of Defect size of lesion $71.4 \pm 47.1$ and 76 \pm 53.2 . Conclusions: The above study showed that the e-TEP repair had shown promising results and was being widely accepted. It results less presence of co-morbidities and less complications when compared to IPOM repair.
\end{abstract}

Keywords:- Ventral hernia, e-TEP, IPOM.

\section{INTRODUCTION}

A ventral hernia is a hernia which can be occur at any location along the midline (vertical center) of the abdomen wall.[1] It is a bulge of tissues through an opening of weakness within the abdominal wall muscles. It can be classified as spontaneous (primary) or acquired (secondary). Also, there are basically 3 types of ventral hernia and these are: Epigastric or stomach area hernia which can occur anywhere from just below the breastbone to the navel or belly button, Umbilical or belly button hernia which can occur in the belly button area and the Incisional hernia can develop at the site of a previous surgery.[1] According to UCSF, approximately one-third of patients who had undergone any abdominal 
Annals of International Medical and Dental Research

E-ISSN: 2395-2822 | P-ISSN: 2395-2814

Vol-8, Issue-2 | March-April 2022

DOI: 10.53339/aimdr.2022.8.2.21

Page no- 157-163 | Section- Research Article (General Surgery)

surgery have the chance of developing an incisional hernia at the site of their scar, which can occur any time after an abdominal surgery. The scar tissue weakens or thins, allowing a bulge to form in the abdomen. This bulge is tissue or organs pushing against the abdominal wall. This is common in both men and women or by their site on the abdominal wall. Hernias are mainly formed due to obesity, other comorbidities, wound infections, immunosuppression, and prostatism.[1] However, there are five laparoscopic treatment methods are available currently for repairing an inguinal hernia and these are: TEP or totally extraperitoneal repair, e-TEP extended view totally extraperitoneal, TAPP or transabdominal preperitoneal, IPOM or intraperitoneal onlay mesh, and reduction of the sac with or without closure of the ring. Studies had found that hernia repair is one of the most common surgical procedures as more than 20 million incidence occurs per year across the world. [2,3] In this study, the two most common methods for ventral hernia repair e-TEP and IPOM had been analyzed comparatively. The e-TEP is the procedure which involves retrorectus spaces opening along with the preperitoneal spaces of Retzius and Bogros at the groin level. It is a useful technique that Jorge Daes first introduced in 2012 in order to address difficult inguinal hernias. [2] This creates opportunity for surgeons to explore the possibility of using the retro-rectus space for ventral hernia repair. The purpose was to create a larger space than what is done in TEP to tackle large groin hernias. Some surgeons have extended the indication to ventral hernias with the purpose to place the mesh in the retro muscular space, as suggested by Rives and Stoppa (RS).[3] The IPOM or Intraperitoneal onlay Mesh is a special repair technique where a mesh is introduced into the abdominal cavity and placed from the inside over the hernia opening. Firstly, a small incision is made in the scar-free abdominal wall then gas is blown into the abdomen to assure better visibility. After this, an instrument with a small camera is introduced and in this way the surgeon has a clear view on a monitor of the surgical field and the various procedural steps.

\section{Objective}

The aim of the study was to compare laparoscopic e-TEP \& IPOM hernia repair in non-complicated ventral hernia

\section{MATERIAL AND METHODS}

This was a prospective observational comparative study. The total sample size for this study 38 and among these 18 cases were from e-TEP and 20 cases were from IPOM. The study period was from December 2019December 2021. The stratified sampling method was followed for this study as an eligibility criterion for age of the respondents was set for this study. Then the patients who undergone hernia repair treatment were randomly included in this study. Inclusion Criteria were Adult patient, Primary ventral or incisional hernia defects, Midline defect with an expected hernia width equal to or less than 7 centimeters, Elective hernia repair, Considered eligible for hernia repair through a minimally-invasive approach, Able to tolerate general anesthesia, Able to give consent for participation. Exclusion Criteria were Defects greater than 7 centimeters, Hernia defects considered to require an open approach, Prior mesh placement in the retro rectus space, 
Annals of International Medical and Dental Research

E-ISSN: 2395-2822 | P-ISSN: 2395-2814

Vol-8, Issue-2 | March-April 2022

DOI: 10.53339/aimdr.2022.8.2.21

Page no- 157-163 | Section- Research Article (General Surgery)

Patients not able to understand and sign a written consent form. After fulfilling the inclusion criteria of the study, written informed consent were taken about their willingness to participate in study and also, they were informed regarding method by which they would be operated upon. Then the data was collected regarding the clinical history, examination, diagnosis, investigations, detail of previous operative procedure from the proper authority.

\section{RESULTS}

The [Table 1] shows the demographic characteristics of the respondents. In age group 18-27, $2(11.11 \%)$ were in e- TEP and 2(10\%) were in IPOM and followed by $5(27.78 \%)$ and $6(30 \%)$ were in age group $28-37,7(38.89 \%)$ and $9(45 \%)$ were in age group which shows the highest participation in both techniques and $4(22.22 \%)$ and $3(15 \%)$ were $>47$. Among the participants, there were $10(55.56 \%)$ male who received e-TEP and $11(55 \%)$ received IPOM treatment and followed by female were $8(44.44 \%)$ and $9(45 \%)$. The Mean \pm SD of the BIM was 25.3 \pm 3.9 for e-TEP and 27.3.2 for IPOM. The [Table 2] shows the clinical history of the respondents. The presence of comorbidities was found in both e-TEP and IPOM. High blood pressure was seen in $7(38.89 \%)$ cases in e-TEP and $8(40 \%)$ cases in IPOM and followed by stroke in $4(22.22 \%)$ and $5(25 \%)$, Hypothyroidism in $1(5.56 \%)$ and $1(5 \%)$, Cancer in 2(11.11\%) and 2(10\%), Diabetes in $4(22.225)$ and $4(20 \%)$. Location of Hernia in right $7(38.89 \%)$ and $8(40 \%)$ and in left side was $11(61.11 \%)$ and $12(60 \%)$. In assessing the condition of disease, it was found that ventral hernia was in $4(22.22 \%)$ and $5(25 \%)$, Umbilical hernia in $6(33.33 \%)$ and $6(30 \%)$, Epigastric hernia 8(44.44\%) and 9(45\%). The Mean and SD of Defect size of lesion $71.4 \pm 47.1$ and $76 \pm 53.2$. The [Table 3] shows the complications that the respondents faced in both e-TEP and IPOM. Surgical site infection was $2(11.11 \%)$ in e-TEP and $2(10 \%)$ in IPOM and followed by seroma in $8(44.44 \%)$ and $2(10 \%)$, Postoperative ileus in $2(11.11 \%)$ and $6(30 \%)$, Bowel or Viscera injury in $1(5.56 \%)$ and $1(5 \%)$, vascular complication in $1(5.56 \%)$ and $1(5 \%)$, Mesh infection in $1(5.56 \%)$ and $1(5 \%)$, Recurrence in 2(11.11\%) and $6(30 \%)$ and Chronic abdominal pain in in $1(5.56 \%)$ and $1(5 \%)$.

Table 1: Demographic characteristics of the respondents.

\begin{tabular}{|l|l|l|l|l|l|}
\hline \multicolumn{2}{|l|}{ Demographic characteristics } & e-TEP(n=18) & $\mathbf{( \% )}$ & IPOM(n=20) & $(\boldsymbol{\%})$ \\
\hline \multirow{5}{*}{ Age } & $18-27$ & 2 & 11.11 & 2 & 10 \\
\cline { 2 - 6 } & $28-37$ & 5 & 27.78 & 6 & 30 \\
\cline { 2 - 6 } & $38-47$ & 7 & 38.89 & 9 & 45 \\
\cline { 2 - 6 } & $>47$ & 4 & 22.22 & 3 & 15 \\
\hline \multirow{2}{*}{ Gender } & Male & 10 & 55.56 & 11 & 55 \\
\cline { 2 - 6 } & Female & 8 & 44.44 & 9 & 45 \\
\hline \multicolumn{2}{|l|}{ BIM (mean } \\
\cline { 2 - 6 }
\end{tabular}


Annals of International Medical and Dental Research

E-ISSN: 2395-2822 | P-ISSN: 2395-2814

Vol-8, Issue-2 | March-April 2022

DOI: 10.53339/aimdr.2022.8.2.21

Page no- 157-163 | Section- Research Article (General Surgery)

Table 2: The clinical history of the respondents.

\begin{tabular}{|c|c|c|c|c|c|}
\hline \multicolumn{2}{|l|}{ Clinical history } & e-TEP $(n=18)$ & $(\%)$ & IPOM $(n=20)$ & $(\%)$ \\
\hline \multirow[t]{5}{*}{ Presence of Co-morbidities } & High blood pressure & 7 & 38.89 & 8 & 40 \\
\hline & Stroke & 4 & 22.22 & 5 & 25 \\
\hline & Hypothyroidism & 1 & 5.56 & 1 & 5 \\
\hline & Cancer & 2 & 11.11 & 2 & 10 \\
\hline & Diabetes & 4 & 22.22 & 4 & 20 \\
\hline \multirow[t]{2}{*}{ Location of Hernia } & Right & 7 & 38.89 & 8 & 40 \\
\hline & Left & 11 & 61.11 & 12 & 60 \\
\hline \multirow[t]{3}{*}{ Condition of disease } & Ventral hernia & 4 & 22.22 & 5 & 25 \\
\hline & Umbilical hernia & 6 & 33.33 & 6 & 30 \\
\hline & Epigastric hernia & 8 & 44.44 & 9 & 45 \\
\hline \multicolumn{2}{|l|}{ Defect size of lesion } & \multicolumn{2}{|l|}{$71.4 \pm 47.1$} & \multicolumn{2}{|l|}{$76 \pm 53.2$} \\
\hline Treatment procedure & & 18 & 100 & 20 & 100 \\
\hline
\end{tabular}

Table 3: Complication of the Respondents

\begin{tabular}{|l|l|l|l|l|}
\hline Complications & e-TEP $(\mathbf{n = 1 8})$ & $\mathbf{( \% )}$ & IPOM $(\mathbf{n}=\mathbf{2 0})$ & $\mathbf{( \% )}$ \\
\hline Surgical site infection & 2 & 11.11 & 2 & 10 \\
\hline Seroma & 8 & 44.44 & 2 & 10 \\
\hline Postoperative ileus & 2 & 11.11 & 6 & 30 \\
\hline Bowel or Viscera injury & 1 & 5.56 & 1 & 5 \\
\hline Vascular complication & 1 & 5.56 & 1 & 5 \\
\hline Mesh Infection & 1 & 5.56 & 1 & 5 \\
\hline Recurrence & 2 & 11.11 & 6 & 30 \\
\hline Chronic abdominal pain & 1 & 5.56 & 1 & 5 \\
\hline
\end{tabular}

\section{DISCUSSION}

Nowadays, there are so many different options to repair ventral hernia-from open ones with different mesh positions to various minimally invasive techniques. Most of these techniques were developed in the last decade. [4] But decision-making process in ventral hernia surgery becomes very difficult due to the variety of techniques and levels of mesh positioning. Several different techniques with different mesh positions are as mentioned above. $[5,6,7]$ Management of giant ventral hernias was challenging due first to the diversity of clinical presentations and numerous therapeutic possibilities and second to the mortality associated with large ventral hernia repair, which could exceed rates observed for neoplastic pathologies. $\frac{[8,9,10,11,12]}{}$ This study basically showed a comparison between the two-treatment technique the eTEP and IPOM. The retro muscular e-TEP technique has not only the benefits of the sub lay position of the mesh but also all the advantages from the minimal invasiveness of the procedure. Besides, avoiding foreign bodies in the abdominal cavity would result in less complications due to the procedure.13] In a study, advantages of IPOM procedure without compromising the recurrence rates had shown 
Annals of International Medical and Dental Research

E-ISSN: 2395-2822 | P-ISSN: 2395-2814

Vol-8, Issue-2 | March-April 2022

DOI: 10.53339/aimdr.2022.8.2.21

Page no- 157-163 | Section- Research Article (General Surgery)

through several randomized control trails and meta-analyses.[14]

In this study there were a total of 38 respondents (e-TEP-18 and IPOM-20). In age group 18-27, $11.11 \%$ were in e- TEP and $10 \%$ were in IPOM and followed by $27.78 \%$ and $30 \%$ were in age group $28-37,38.89 \%$ and $45 \%$ were in age group which shows the highest participation in both techniques and 22.22\% and $15 \%$ were $>47$. Among the participants, there were $55.56 \%$ male who received e-TEP and 55\% received IPOM treatment and followed by female were $44.44 \%$ and $45 \%$. The Mean \pm SD of the BIM was $25.3 \pm 3.9$ for e-TEP and 27.3.2 for IPOM. [Table 1] A similar study was conducted by Dr. Jignesh Joshi, Dr. Firdaus Dekhaiya where they analyzed 60 cases, 30 case under e-TEP and 30 cases under IPOM treatment technique.[15] Another study by D. Penchev, G. Kotashev and V. Mutafchiyski showed the BIM 25.1 \pm 3.9 and 27.1 \pm 3.2 .[16] In this study, the presence of comorbidities was found in both e-TEP and IPOM. High blood pressure was seen in 38.89\% cases in e-TEP and $40 \%$ cases in IPOM and followed by stroke in $22.22 \%$ and $25 \%$, Hypothyroidism in 5.56\% and 5\%, Cancer in $11.11 \%$ and $10 \%$, Diabetes in $22.22 \%$ and $20 \%$. [Table 2] In a similar study conducted by D. Penchev, G. Kotashev and V. Mutafchiyski it was found that the diabetes was present in 2 cases under e-TEP and 1 case under IPOM.16 Location of Hernia in right $38.89 \%$ and $40 \%$ and in left side was $61.11 \%$ and $60 \%$. In assessing the condition of disease, it was found that ventral hernia was in $22.22 \%$ and $25 \%$, Umbilical hernia in $33.33 \%$ and 30\%, Epigastric hernia $44.44 \%$ and $45 \%$. The Mean and SD of Defect size of lesion $71.4 \pm 47.1$ and $76 \pm 53.2$ which is similar with the study of D. Penchev, G. Kotashev and V. Mutafchiyski.[16] In this study, the surgical site infection was $11.11 \%$ in e-TEP and $10 \%$ in IPOM and followed by seroma in $44.44 \%$ and $10 \%$, Postoperative ileus in $11.11 \%$ and $30 \%$, Bowel or Viscera injury in $5.56 \%$ and $5 \%$, vascular complication in 5.56\% and $5 \%$, Mesh infection in $5.56 \%$ and $5 \%$, Recurrence in $11.11 \%$ and $30 \%$ and Chronic abdominal pain in in 5.56\% and 5\%. [Table 3] A study showed IPOM is associated with increased risk of bowel injury, ASBO, bowel erosion and increased morbidity in redo surgery with the risk of visceral injury going up to $21 \%$.117] Belyansky et al. reported 79 cases under e-TEP and only three postoperative complications - two of them seroma and one dehiscence at port site without SSI. The recurrence rate in this study is $1.3 \%$.[18] The study also claimed that, IPOM might not always reduce pain or improve the quality of life in comparison with most minimally invasive procedures. [19] The study also predicts that lack of fixation in e-TEP procedure can be a reason for reduced postoperative pain. In some studies, the relationship between aggressive double crown fixation and/or transfascial sutures and postoperative pain is found.[20] Some studies also showed significant rate of acute postoperative and chronic pain. [21,22] In some study, several limitations of the e-TEP procedure was also found. First of all, the e-TEP is not suitable for large and complex ventral hernias especially where abdominal wall reconstruction is essential. Besides, the procedure can be extremely difficult in patient with multiple small defects. However, the e-TEP technique is quite new and hence longer-term follow-up and recurrences had not been evaluated properly 


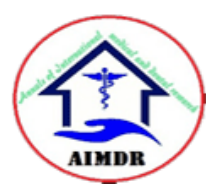

Annals of International Medical and Dental Research

E-ISSN: 2395-2822 | P-ISSN: 2395-2814

Vol-8, Issue-2 | March-April 2022

DOI: 10.53339/aimdr.2022.8.2.21

Page no- 157-163 | Section- Research Article (General Surgery)

till now.[23] Some studies also emphasized based on some current evidence that there might be a bias as the results are from a highvolume hernia center which were performed by the top experts in the field. A study emphasized on the proper designed prospective randomized trial in order to bring some strong evidence in this regard.[23] However, in some studies, there are also claimed that the e-TEP should not be considered as an overkill for a small hernia defect, which needs sufficient mesh coverage of at least $5 \mathrm{~cm}$ in each direction compared to the IPOM technique. [24,25]

\section{REFERENCES}

1. Akkary E, Panait L, Roberts K, Duffy A, Bell R. Sutureless laparoscopic ventral hernia repair in obese patients. JSLS. 2011;15(2):154-159. doi:10.4293/108680811X13022985131859

2. Daes J. The enhanced view-totally extraperitoneal technique for repair of inguinal hernia. Surg Endosc. 2012;26(4):1187-9. doi: 10.1007/s00464-011-1993-6.

3. Belyansky I, Daes J, Radu VG, Balasubramanian R, Reza Zahiri H, Weltz AS, et al. A novel approach using the enhanced-view totally extraperitoneal (eTEP) technique for laparoscopic retromuscular hernia repair. Surg Endosc. 2018;32(3):1525-1532. doi: 10.1007/s00464-017-5840-2.

4. Vorst AL, Kaoutzanis C, Carbonell AM, Franz MG. Evolution and advances in laparoscopic ventral and incisional hernia repair. World J Gastrointest Surg. 2015;7(11):293-305. doi: 10.4240/wjgs.v7.i11.293.

5. Bellido Luque J, Bellido Luque A, Valdivia J, Suarez Gráu JM, Gomez Menchero J, García Moreno J, et al. Totally endoscopic surgery on diastasis recti associated with midline hernias. The advantages of a minimally invasive approach. Prospective cohort study. Hernia. 2015;19(3):493-501. doi: 10.1007/s10029-014-1300-2.

6. Schwarz J, Reinpold W, Bittner R. Endoscopic mini/less open sublay technique (EMILOS)-a new technique for ventral hernia repair. Langenbecks

\section{CONCLUSIONS}

The above study showed that the e-TEP repair had shown promising results and was being widely accepted. It results less presence of comorbidities and less complications when compared to IPOM repair which results in less overall cost of treatment procedure, faster return to normal daily activity, lower rate of postoperative complications and low rate of recurrence as compared to IPOM ventral hernia repair. Hence, the e-TEP repair is considered as first choice for ventral hernia repair in most of the studies.

Arch Surg. 2017;402(1):173-180. doi: 10.1007/s00423016-1522-0.

7. Orthopoulos G, Kudsi OY. Feasibility of RoboticAssisted Transabdominal Preperitoneal Ventral Hernia Repair. J Laparoendosc Adv Surg Tech A. 2018;28(4):434-438. doi: 10.1089/lap.2017.0595.

8. Goñi Moreno I. Neumoperitoneo apicdo a la preparación quirúrgica de las grandes eventraciones crónicas Pneumoperitoneum applied to the surgical preparation of large chronic eventrations. Prensa Med Argent. 1971 Jul 23;58(21):1037-41.

9. Ramirez OM, Ruas E, Dellon AL. "Components separation" method for closure of abdominal-wall defects: an anatomic and clinical study. Plast Reconstr Surg. 1990;86(3):519-26. doi: 10.1097/00006534-199009000-00023.

10. Dennis A, Vizinas TA, Joseph K, Kingsley S, Bokhari F, Starr F, et al. Not so fast to skin graft: transabdominal wall traction closes most "domain loss" abdomens in the acute setting. J Trauma Acute Care Surg. 2013;74(6):1486-92. doi: 10.1097/TA.0b013e3182924950.

11. Van Geffen HJ, Simmermacher RK. Incisional hernia repair: abdominoplasty, tissue expansion, and methods of augmentation. World J Surg. 2005;29(8):1080-5. doi: 10.1007/s00268-005-7972-0.

12. Sabbagh C, Dumont F, Robert B, Badaoui R, Verhaeghe P, Regimbeau JM. Peritoneal volume is predictive of tension-free fascia closure of large 
Annals of International Medical and Dental Research E-ISSN: 2395-2822 | P-ISSN: 2395-2814

Vol-8, Issue-2 | March-April 2022

DOI: 10.53339/aimdr.2022.8.2.21

Page no- 157-163 | Section- Research Article (General Surgery)

incisional hernias with loss of domain: a prospective study. Hernia. 2011;15(5):559-65. doi: 10.1007/s10029-011-0832-y.

13. Iqbal CW, Pham TH, Joseph A, Mai J, Thompson GB, Sarr MG. Long-term outcome of 254 complex incisional hernia repairs using the modified RivesStoppa technique. World J Surg. 2007;31(12):2398404. doi: 10.1007/s00268-007-9260-7.

14. Forbes SS, Eskicioglu C, McLeod RS, Okrainec A. Meta-analysis of randomized controlled trials comparing open and laparoscopic ventral and incisional hernia repair with mesh. Br J Surg. 2009;96(8):851-8. doi: 10.1002/bjs.6668.

15. D. Penchev, G. Kotashev, V. Mutafchiyski, Endoscopic enhanced-view totally extraperitoneal retromuscular approach for ventral hernia repair. Surg Endosc. 2019; 33:3749-3756 https://doi.org/10.1007/s00464-019-06669-2

16. Joshi J, Dekhaiya F. A Comparative Study between E-TEP Versus IPOM Hernia Repair. 2020;19(3):19-21.

17. Jenkins ED, Yom V, Melman L, Brunt LM, Eagon JC, Frisella MM, Matthews BD. Prospective evaluation of adhesion characteristics to intraperitoneal mesh and adhesiolysis-related complications during laparoscopic re-exploration after prior ventral hernia repair. Surg Endosc. 2010;24(12):3002-7. doi: 10.1007/s00464-010-1076-0.

18. Belyansky I, Daes J, Radu V, Balasubramanian R, Zahiri H, Weltz A, et al. A novel approach using the enhanced-view totally extraperitoneal (eTEP) technique for laparoscopic retromuscular hernia repair. Surg Endosc. 2018;32(3):1525-1532.

19. Eriksen JR, Poornoroozy P, Jørgensen LN, Jacobsen B, Friis-Andersen HU, Rosenberg J. Pain, quality of life and recovery after laparoscopic ventral hernia repair. Hernia. 2009;13(1):13-21. doi: 10.1007/s10029. 008-0414-9.

20. Brill JB, Turner PL. Long-term outcomes with transfascial sutures versus tacks in laparoscopic ventral hernia repair: a review. Am Surg. 2011;77(4):458-65.

21. Nguyen SQ, Divino CM, Buch KE, Schnur J, Weber KJ, Katz LB, Reiner MA, Aldoroty RA, Herron DM. Postoperative pain after laparoscopic ventral hernia repair: a prospective comparison of sutures versus tacks. JSLS. 2008;12(2):113-6.

22. Wassenaar EB, Raymakers JT, Rakic S. Removal of transabdominal sutures for chronic pain after laparoscopic ventral and incisional hernia repair. Surg Laparosc Endosc Percutan Tech. 2007;17(6):5146. doi: 10.1097/SLE.0b013e3181462b9e.

23. Belyansky I, Reza Zahiri H, Sanford Z, Weltz AS, Park A. Early operative outcomes of endoscopic (eTEP access) robotic-assisted retromuscular abdominal wall hernia repair. Hernia. 2018;22(5):837-847. doi: 10.1007/s10029-018-1795-z.

24. Kaufmann R, Halm J, Eker H, Klitsie P, Nieuwenhuizen J, Geldere D, et al. Mesh versus suture repair of umbilical hernia in adults: a randomised, double-blind, controlled, multicentre trial. Lancet. 2018;391:860-869

25. Earle D, Roth JS, Saber A, Haggerty S, Bradley JF 3rd, Fanelli R, et al; SAGES Guidelines Committee. SAGES guidelines for laparoscopic ventral hernia repair. Surg Endosc. 2016;30(8):3163-83. doi: 10.1007/s00464-016-5072-x.

Source of Support: Nil, Conflict of Interest: None declared 